\title{
Project-based experience through real manufacturing activities in mechanical engineering
}

\begin{abstract}
As reported by many professional bodies responsible for accrediting engineering programs, today's engineering graduates present important limitations in the practice of engineering because current engineering curricula is still too focused on fundamental engineering science without providing sufficient integration to industrial practice. To overcome these limitations, active learning approaches have been applied in the literature with positive results in engagement, motivation and student's performance. In this paper, we propose a project based learning approach with real manufacturing activities in a 4-year mechanical course to improve the learning process. The goal of the project is to plan the manufacturing process of a real part and conduct at shop-floor levels all the activities required. The experience was evaluated considering project/exam grades, questionnaires and manufacturing quality. The results showed an increase in student's satisfaction, improvement in the exam performance, and a clearly increase in student's enrolment in the manufacturing master degree.
\end{abstract}

Keywords: active learning; project-based; engineering education; manufacturing; mechanical engineering; experiential learning.

\section{Introduction}

In recent years studies have been conducted in many countries to determine the technical and personal abilities required of engineers by today's industry. In 2006, the seminal Henley Report (1) was commissioned by the Royal Academy of Engineering and surveyed over 400 engineering companies within the United Kingdom. This report identified several limitations of current undergraduate engineering education and it was remarked the low ability of engineering graduates to apply knowledge to industry problems. Previously, an Education White Paper in 2001 (2) claimed that the dominant mode of teaching and learning in higher education is based on "teaching as telling; learning as recall", which do not help students to acquire two kinds of learning that are considered crucial to their individual success in our society: real understanding and habits to be caring citizens. These qualities are acquired through pedagogies that require intense engagement. Other key concerns identified by many authors in today's engineering graduates are (1-3):

- lack of communication skills and teamwork experience;

- need to be more awareness of social, environmental, economic and legal issues that are part of the reality of modern engineering practice;

- inability to apply engineering solutions in practice despite of having a good knowledge of fundamental engineering science.

Therefore, there is a general agreement that current engineering curricula are too focused on fundamental engineering science without providing sufficient integration of these topics or relating them to industrial practice. Real engineering experiences are not sufficient in current programs and the student engagement and motivation is an important issue since teaching and learning strategies are still teacher-centred (3).

Due to these deficiencies in recent engineering graduates, professional bodies such as Engineers Australia (EA) in Australia, Accreditation Board of Engineering and Technology (ABET) in America, and the European Networks for Accreditation of Engineering Education (ENAEE) in Europe have defined a list of expected graduate attributes or outcomes that should be incorporated in the educational programs in order to obtain the accreditation of an Engineering Program. For instance, ENAEE sets the program outcomes in terms of knowledge, understanding, skills and abilities that a graduate must demonstrate within an accredited engineering degree program. The program outcomes are described with reference to the following eight learning areas: knowledge and understanding; engineering analysis; engineering design; investigations; engineering practice; making judgments; communication/team-working and lifelong learning (4). 
It turns out to be interesting that despite the large body of education research that has demonstrated the ineffectiveness of engineering education based on "chalk and talk" $(1-3,5-7)$, it is in recent years when the educational institutions are really moving to adopt new pedagogical strategies, mainly because of the step forward given by the bodies responsible for accrediting engineering programs.

As stated above, the teacher-centred learning approach is still predominant in engineering educational where the instructor acts as a mere transmitter of information and the students passively absorb information and knowledge without typically engaging with the information received. This approach, also called passive learning approach, may prepare the students to pass the exam in short term but it presents important issues related to low knowledge retention, difficulties in the engagement of the students, lack of motivation, and low preparation for the 'practice of engineering' (8).

In order to overcome these limitations, new learning methodologies such as problem-based learning or project-based learning, to name few of them, have been proposed within the so-called active learning approach. By this instructional approach students are involved in doing things and thinking about the things they are doing (9) and makes students an active participant in the process of assimilating new information. Although the methodologies based on active learning were developed long time ago and many previous investigations had already shown their benefits, it seems that only few years ago a comprehensive and quantitative analysis conducted by Freeman et al. (10) has proven the positive impact of active learning methods versus exposition centred methods in undergraduate engineering courses. Previously, Prince et al (11) conducted a less comprehensive research and claimed similar benefits when active learning approaches are applied. In general, these studies identify the following positive aspects of active learning methods:

- Students learn the material and perform better on exams and are 1.5 times less likely to fail than students in classes with traditional lectures.

- Collaboration with classmates builds community and a sense of belonging among students, which can enhance motivation and persistence.

- Authentic problems and case studies can motivate students and keep them actively engaged in their learning tasks.

- Having to analyse complex situations also promotes the students' adoption of a deep approach to learning, while rote memorization and simple algorithmic substitution are clearly inadequate strategies for dealing with such situations.

- The levels of student attendance and retention increases in comparison to traditional lectures.

In the literature a large number of active learning methodologies can be found $(9,12)$. However, we can consider the inductive learning methods shown in Figure 1 as the most common approaches implemented in the field of engineering. The main characteristics of these approaches are:

- Inquiry Learning (IL). In IL the instruction is modified to promote the learning by answering questions and solving problems (11). As the students gain more experience with this approach, the instructor may increase the scope and difficulty of the focus questions, use more open-ended and ill-structured problems and simultaneously decrease the amount of explicit guidance provided. Some recent experiences in IL can be found in (13-15).

- Just-in time learning (JiTT). In JiTT, students respond to conceptual questions before each class about material not yet covered and the instructor adjusts the lesson of each class to react to misconceptions revealed by students' responses (16). This methodology was applied in a biology course by Marrs and Novak (17) where an improvement of test performance before and after class was reported together with a better knowledge retention and classroom interactivity. Similar conclusions were derived by Slunt and Giancarlo (18) in general chemistry and organic chemistry courses. However, this 
methodology requires important efforts from instructors and flexibility to change and adapt lessons at any time (16) and it is not usually applied in engineering education.

- Problem based learning (PBL). PBL begins when students are confronted with an open-ended, ill-structured, authentic (real-world) problem and work in teams to identify learning needs and develop a viable solution, with instructors acting as facilitators rather than primary sources of information (11). However, according to Perrenet et al. (19), PBL methodologies seem to be less appropriate since recent research on misconceptions suggest that may not always lead to constructing the "right" knowledge. The approach could work fine in other domains such as medicine where its encyclopaedic structure makes no critical the order in which various concepts are encountered and further learning will hardly be affected by missing a topic at a specific point in time. An interesting review of this learning method can be found in (20).

- Case-based learning (CBL). In CBL students analyse case studies of historical or hypothetical situations that involve solving problems and/or making decisions. The idea is that in analysing complex authentic cases, the students become aware of the kinds of situations and dilemmas they might have to face as professionals, gain both theoretical and practical understanding of their subjects, develop critical reasoning skills, explore their existing preconceptions, beliefs, and patterns of thinking, and make necessary modifications in those preconceptions, beliefs, and patterns to accommodate the realities of the cases (11). This approach let the instructor teach basic concepts and problemsolving skills, and provide engineering experience to students (21). However, despite the popularity of case study approach in fields such as business (22), the use of case-based learning in the engineering field is quite limited and most of them have been primarily focused on student perceptions of their learning rather than actual learning outcomes (11).

- Experiential learning (EL). The EL follows the well-known Kolb's Experiential learning cycle, where learners should involve themselves in new experiences, observe and reflect on them, create concepts that integrate their observations into logically sound theories and finally they must be able to use these theories to make decisions and solve problems (23). Some experiences can be found in the literature about this learning approach, mainly in laboratory with mechatronics devices $(24,25)$.

- Project based learning (PjBL): In PjBL, the students apply and assimilate previously acquired knowledge by doing actual projects. PjBL begins with an assignment to carry out one or more tasks that lead to the production of a final product- a design, a model, a device or a computer simulation. The culmination of the project is normally a written and/or oral report summarizing the procedure used to produce the product and presenting the outcome (11). In the literature, PjBL is also called Design-based learning (DBL) when the project is focused on the active cooperation of students in design tasks with the purpose of designing new products and systems with increased performance (26). Readers interested in DBL approaches can refer to reviews in $(27,28)$.

- Learning Factories (LFs). The Learning Factory was firstly coined and patented in 1994 by Penn State University and it refers to interdisciplinary hands-on senior engineering design projects with strong links and interactions with industry (44). Basically, the idea of learning factories is to train engineering students through hands-on experiences at university facilities that recreate real factories. LFs are commonly based on experiential learning or project-based learning methods and they are well-suited to integrate design and manufacturing issues and provide previously unavailable opportunities for hands-on engineering experience in the Learning Factory (45). 


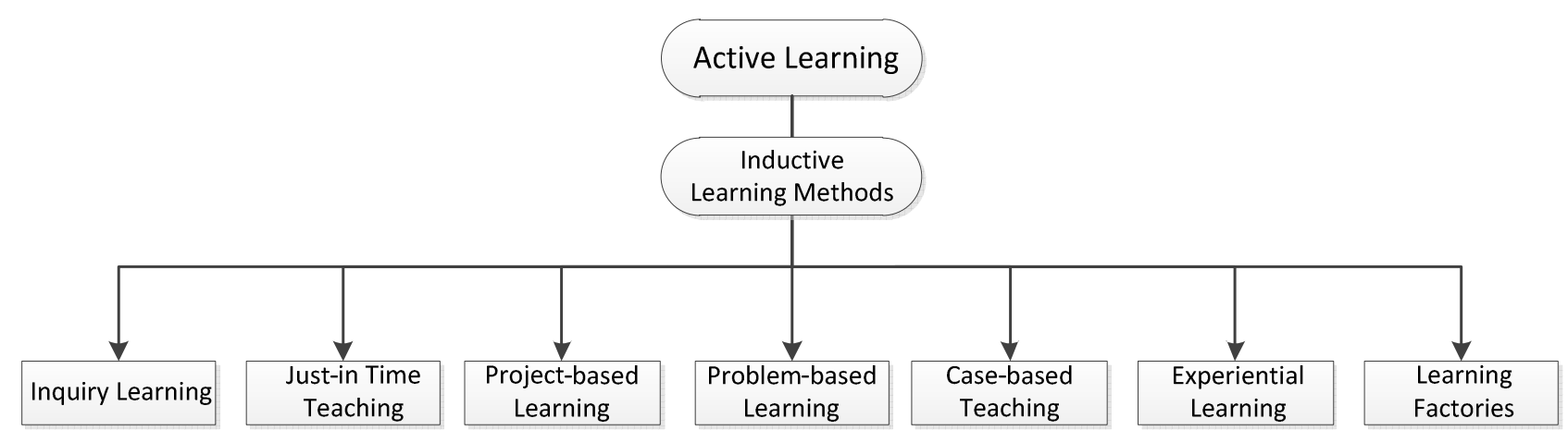

Figure 1. Some active learning approaches applied in Engineering Education.

\section{Project-based Learning in Engineering Education}

Although previous approaches have been applied in engineering education, $\mathrm{PjBL}$ is the active learning approach most widely used mainly because project tasks are closer to professional reality in engineering. Furthermore, project work is more directed to the application of knowledge whereas other approaches such as problem-based learning is more directed to the acquisition of knowledge $(3,19)$. Excellent reviews of PjBL are given in (29-31) where it is reviewed some of the main factors influencing the success of project-based learning experiences at higher education such as those that are likely to affect motivation and thought, difficulties that students and teachers may encounter with projects or how to effectively design the project experience.

Other educational experiences that reinforce the benefits of this learning approach have been also reported in engineering education. In (32), the authors introduced the PjBL approach in an introductive course on mechanical engineering with the aim of simulating the process of design and development of a new product, and emotionally engage students in this process. During the course, students worked in small groups to design and built a device that performs a specific task and the quality of the designs was evaluated through a competition among all groups. After the competition, each team was required to submit a final technical report detailing the research and development process, the engineering considerations that led to the final design, a review of the relevant engineering literature, and the team's conclusions. The authors gathered data from students and instructors interviews, observations in the classroom and students' reports to study the students' perceptions in a PjBL environment. According to students' opinion, the course helped to develop their engineering thinking and their intuition, increased motivation to study and made them feel like responsible collaborators in the learning process. However, the study was only based on students' perceptions, with no objective evaluation of the benefits of the PjBL approach. Hadim et al. (33) presented the implementation of the PjBL approach in a first-year course on Mechanics of Solids and a second-year course on Mechanism and Machine Dynamics. The project was related to the design and analysis of a tower crane used for lifting heavy loads and it was monitored by periodic reports and instructor's feedback. The implementation of the PjBL required the reduction of homework assignments to $50 \%$ and the material covered by lectures was also reduced to $25 \%$. The assessment of the educational experience was conducted through a survey of the students at the end of the semester. The students increased their motivation and interest of practical illustration of reallife applications but they demanded more guidance in completing the project, which is a critical issue in this kind of learning methodologies. The analysis about the exam performance showed a measurable improvement of the students especially in the examination of design components. Palmer and Hall (34) applied the PjBL approach in a first-year engineering of a bachelor of Engineering Technology, however, they did not find any significant difference in the students' performance although they observed a high students' satisfaction. Similar to other studies the project was focused on engineering design (i.e., mechanical, electrical and civil design projects), and after administering a questionnaire they pointed out that the best aspects of $\mathrm{PjBL}$ according to students' perception were team working and practical approach and the worst aspect was the necessity of more time to work on the project. In this educational experience they also remarked 
common issues related to group work among students and the challenge of how to fairly rate the contribution of each team member. Although they used a self- and peer-assessment (SAPA) procedure to assess each student's contribution to the group, they also suggested a revision of this system for a better work group assessment.

Vila et al. (35) showed an educational experience in a 5-year engineering course on Integrated Manufacturing Technologies. The purpose of the project was: i) design a new component for a given car toy, ii) prototype the component in a 3-D printer in order to validate the component and its assemblability and iii) design the cavity mould for the injection process. The project was conducted through a Product Lifecycle Management (PLM) software and the students/instructors worked following a predefined workflow. The instructors reviewed the students' designs and, using the PLM and a web-browser visualizer, made annotations to correct the designs. The approval for the next stage of the project was given when all corrections were made and no design errors were detected by the instructors. After the project, the students were asked to complete a questionnaire and the authors reported a high engagement where students evaluated positively the experience and acknowledge their high improvement in abilities related to computer aided design, computer aided manufacturing and product data management. In (36), the same authors evaluate different PLM software to support the execution of collaborative practices during the development of project-based learning activities in higher education.

Ignacio de los Ríos et al (37) presented a review of two decades of PjBL experiences in the Technical University of Madrid thank to the collaboration agreement with the regional administration. The educational projects conducted at different course levels were accorded annually by the university and the regional administration, defining projects with real content, which require students to integrate the knowledge they have already gained from other courses with new knowledge attained in developing the project. The project-based methodology was adapted throughout two decades. For instance, the class time for lectures was cut to $50 \%$, the group activities related to the project in class was increased from 5 to 20 hours together with an important increase of on-line tutoring. The authors claimed that $\mathrm{PjBL}$ is the most adequate methodology for the development of competences, linking teaching with the professional sphere. However, according to them a critical issue is the role of both teachers and students who should be more active and, particularly for the students, they have to show greater responsibility for their own learning.

In the field of manufacturing courses, a general problem instructors may find is to keep the students focused on explanations which tend to be very descriptive and theoretical. Even though the frequent use of videos with great explanations such as TV series like How It's Made can increase students' motivation, traditional lecturing generates a lack of real engagement on manufacturing processes. A straight forward solution to overcome this situation is to promote the participation of students in real manufacturing activities by acting as process planners to manufacture predefine parts. For this purpose, Learning Factories have been implemented at colleges which offer students in traditional engineering disciplines an alternative path to a degree that directly prepares them for careers in manufacturing, design and product realization (46). However, the implementation of Learning Factories in small universities without the support of local industries is not feasible and other project-based experiences using basic manufacturing equipment should be considered. For instance, Ssemakula and Liao (46) describe the adaptation of the Learning Factory approach in regular academic programs without having to build an actual factory. They coordinated different projects in five engineering courses where the students generate the CAD drawings of a product, produce the process plans and manufacture and assemble all product components. Similarly, Maliky et al (47) proposed an active learning experience based on hands-on machining/fabrication to integrate the contents of several manufacturing courses. The proposed project-based activities were focused on real products such as acoustic guitar or compressed-air engine and they were fabricated using CNC machine-tools and welding machines. The authors stated that this experience greatly enhanced the development of the students' design and industrial abilities and the student and instructor ratings were very positive. 
Despite of the above literature review, it is important to remark that some authors are sceptical about the usefulness of these approaches. Kirschner et al (38) discussed that minimally guided instruction such as the active methodologies presented above may be less effective and less efficient than instructional approaches. According to their study, only a less guidance of the student learning process is effective when learners have sufficiently high prior knowledge. Therefore, it is critical to consider a good trade-off between guidance and self-discovery when designing efficient active learning approaches.

In this paper we show a PjBL experience conducted in a 4-year course of mechanical engineering degree at the Universitat Jaume I, Castellon, Spain. Through this education experience the students learn from real engineering problems and face real manufacturing issues at shop-floor level. The experience has been conducted for two consecutive academic years and the goal of the project is the manufacturing of a part at the university facilities covering all process planning activities such as creation of sand moulds, sequence of machining operations, cutting-tool and fixture selection, geometric validation through tolerance charting, generation of CNC programs, machining and quality inspection of resulting parts. Therefore, the project-based approach presented in this paper is combined with the experiential learning methodology. We compare the results of this 2-year experience with the results of previous years where the course was taught following other active learning techniques based on short problems and computer sessions not connected to each other and without the goal of manufacturing a real part. By this study we want to analyse the potential effect of conducting real projects, not only based on a final report but also based on the elaboration of physical objects. The elaboration of real objects and the impact of right or wrong decisions on them along the project may increase the engagement of students throughout the course and improve knowledge acquisition and retention.

The paper is organized as follows. First, the hypothesis of the research is exposed together with the scope and goal of the educational experience. Then, the methodology conducted during the semester is explained and the activities, group definitions and grading system are detailed. The sections that follow show the implementation and the results of the educational experience and discuss them to analyse the benefits of this project-based method with real manufacturing activities in comparison with the results from previous years. Finally, the last section presents the conclusions of the research.

\section{Scope and research objectives}

The educational experience is conducted in a 4-year course of mechanical engineering, named Manufacturing Process Planning. The course has 6 ECTS (European Credit Transfer and Accumulation System) which refers to 60 hours with the instructor and 90 autonomous working hours. The contents of the course are: i) introduction to manufacturing process planning, ii) process planning in casting, iii) process planning in machining, iv) economics of process planning.

Four academic courses are analysed in this paper. During the first two years (courses 2014/15 and 2015/16), the course had an important theoretical workload complemented with practical activities with the instructor. For instance, activities in shop-floor were conducted to build sand moulds, computer room activities were given to show how a Computer Aided Manufacturing (CAM) software such as SolidCam works and some activities related to machining were also conducted. However, the role of the student here was limited and in some cases they acted as a mere observer. For instance, the machining activity was just to launch a predefined CNC program, not a program created by the students, or the CAM sessions were used to generate CNC programs for practicing purposes without uploading and launching the CNC program in our machine-tools.

Although the performance and degree of satisfaction of the students was adequate, the methodology was modified for the following courses (courses 2016/17 and 2017/18) in order to have a complete view of the manufacturing process of a part, and the project-based learning approach proposed in this paper was adopted. Unlike the first two years, all manufacturing process 
planning activities learnt along the course were applied to the final purpose of manufacturing a real part. There are no independent or unconnected activities, all computer room and shop-floor activities are centred on manufacturing the part and the role of the student is critical to reach the final purpose since they have to provide the solutions in patterns design, selection of fixturing and cutting-tools, geometric verification, $\mathrm{CNC}$ programs for machine-tools and methodology for part inspection. The role of the instructor is also critical since he has to closely monitor the learning process and review the students' solutions in order to make feasible the manufacturing process.

Readers can notice the challenge of this approach. First, the goal of the project is planning the manufacturing process to ensure that the parts manufactured are within specifications, which involve many different and complex activities such as process planning in casting, in machining, and estimation of cost manufacturing. Secondly, the project should be validated through real experimentation according to students' decisions (pattern design, machining sequence, CNC code, and so on), which makes the students participate in a real manufacturing process development and learn about the errors made.

We believe that this PjBL methodology will increase student's motivation and improve their performance in the exam. In this experience, the following aspects will be analysed in order to quantitatively define the benefits of this type of learning methodology.

- Class attendance

- Students' satisfaction about the course

- Students' performance at the exam according to project performance

- Number of students that stay at the University to conduct a Master degree in manufacturing.

- Instructor's satisfaction

\section{Methodology}

\subsection{Project activities}

As explained in the introductory part, this educational experience shows a PjBL approach where real experimentation is applied. The activities conducted during the project are shown in Figure 2. We basically distinguish four types of activities: lectures, computer room sessions, shopfloor sessions, and seminars. The lectures are given as the traditional approach but the topics are covered at the time the project needs. The computer room sessions are used for learning the software that the students need to apply in the project. For instance, pattern design for casting is conducted using SolidWorks; the files to be printed are checked with Netfabb and the 3D printing process is done with Slic3r; the CNC programs are simulated with CNCSimulator, WinUnisoft and itnc530 software from Heidenhain. The shop-floor activities are used to conduct real manufacturing activities such as 3D printing, sand casting, machining and part inspection. The seminar activities are used to promote the interaction between instructor and students, review the students' solution given in the deliverables, monitor the learning process and ensure that the progress of the project is adequate. Note that a proper guidance in project-based experiences is necessary to obtain an effective learning process (38), and some studies recommend frequent feedback and revision activities to efficiently monitor student work progress $(29,30,41)$. For this project, the students' progress is monitored in three seminars.

After all these activities, the students have to write a final report and give a presentation about the results of the project. The presentation is considered mandatory and should participate all the members of the group. The importance of the presentation is reported in some studies where it is remarked its usefulness to assess the project and to boost global learning since each group see the results of their companions and leads to self-criticism and group discussion $(30,39)$. 


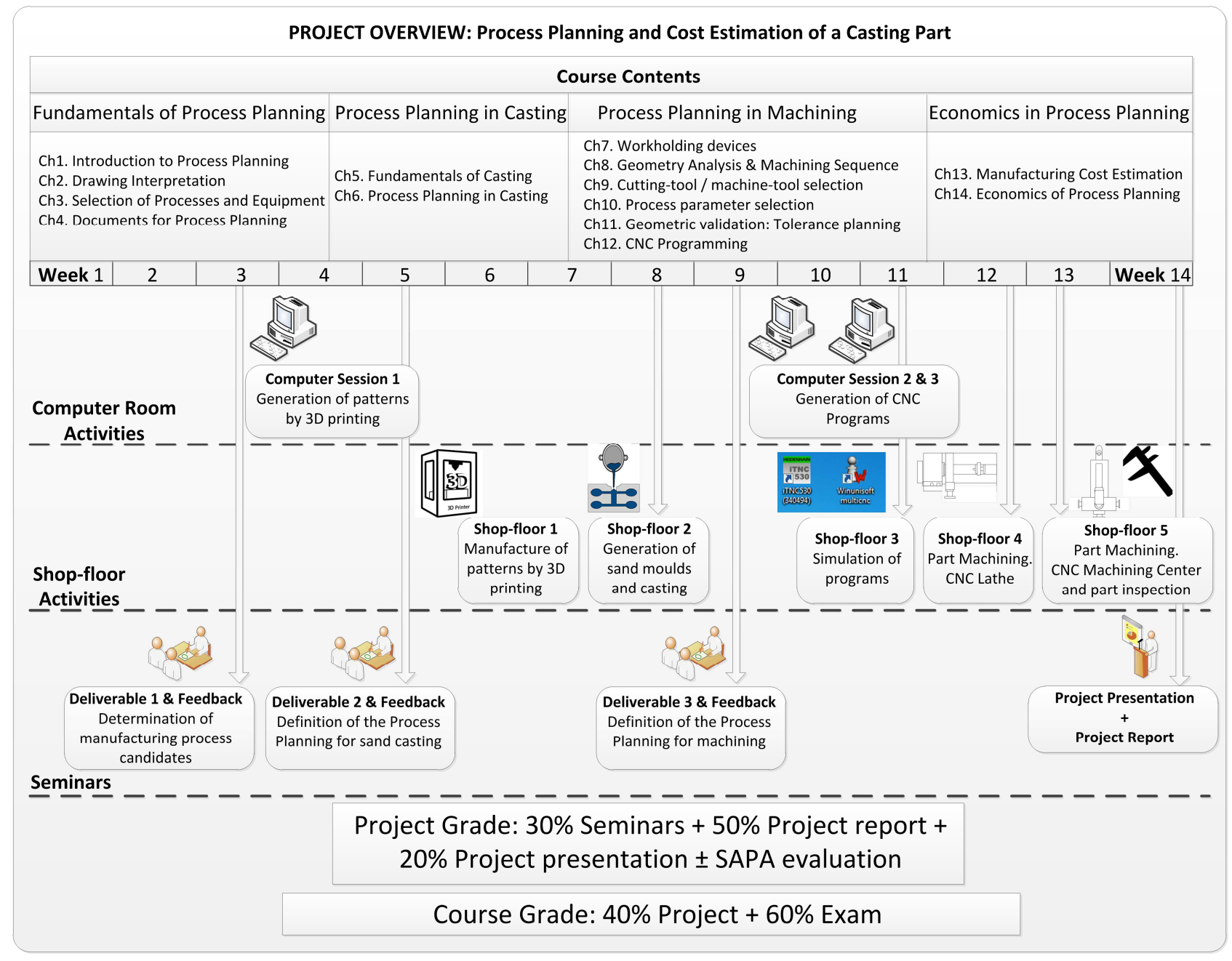

Figure 2. Project Overview. Planning of project activities: computer room, shop-floor, seminars and final project presentation.

\subsection{Project teams definition}

The definition of the members of the group is a key issue for the correct development of a projectbased experience. In the literature, groups of three or four students are commonly recommended whereas larger groups may encourage the appearance of 'parasite' members and make it harder to individualize marks $(29,30)$. In general, it is discouraged to let the students determine the composition of the project teams based on friendships and working relationships from previous courses which can affect the fair evaluation of both individual contributions and the overall team performance (33). Therefore, in this project the groups are composed of 3-4 members and the members of each group are selected by the instructor in a random manner but trying to create groups not very different in terms of students' grading performance, i.e., there are no teams with a priori better performance in students' grades than others.

\subsection{Grading System}

The grading system of the course is based on two grades: the project grade and the exam grade. The project grade accounts $40 \%$ and the exam grade $60 \%$ of the final grade. The course has no midterm or additional homeworks or tests since the workload during the semester is quite high. The exam has two parts: a theoretical part and a practical part, where practical exercises are similar to the ones solved during the project such as manufacturing process selection, geometric verification, machining process planning or CNC programming. The final grade of the project is 
given by the seminars grades $(30 \%)$, the presentation grade $(20 \%)$, and the grade of the final report $(50 \%)$. All the grades in the project are given according to a rubric following Eur-Ace guidelines (4).

In order to deal with groups where some students might have worked less than their companions, the project includes a co-assessment activity where all students have to assess the contribution to the project of each member of the group. According to this information, the final project grade may be adjusted among the members of the group. For instance, if one member of the group has clearly worked much more than all the rest, this student can have up to +1 more in the project grade while the other students in the same group, if we assume a group of 3 students, would have -0.5 points less. This procedure is applied except for special cases where a student has made no contribution whatsoever to the experience. In those cases, the student fails the project. The importance of the co-assessment is reported in the literature to avoid unfair practices among group members $(30,33)$ and it seems reasonable that the co-assessment let the instructor to allocate from $5 \%$ to $15 \%$ of the final mark (30).

\section{Project implementation}

As shown in Figure 2, the project starts at the first week of the semester with the creation of project groups and the definition of the parts that should be manufactured. Figure 3 shows one of the parts that were assigned to the students (one part per group). The activities were conducted according to the planning shown in Figure 2. According to the material, geometrical specifications and production volume, the students decided the best group of manufacturing process candidates to be applied for the assigned part, and the final selection was reasoned. In the first seminar, the students interacted with the instructor to explain the procedure followed and discuss about possible errors.

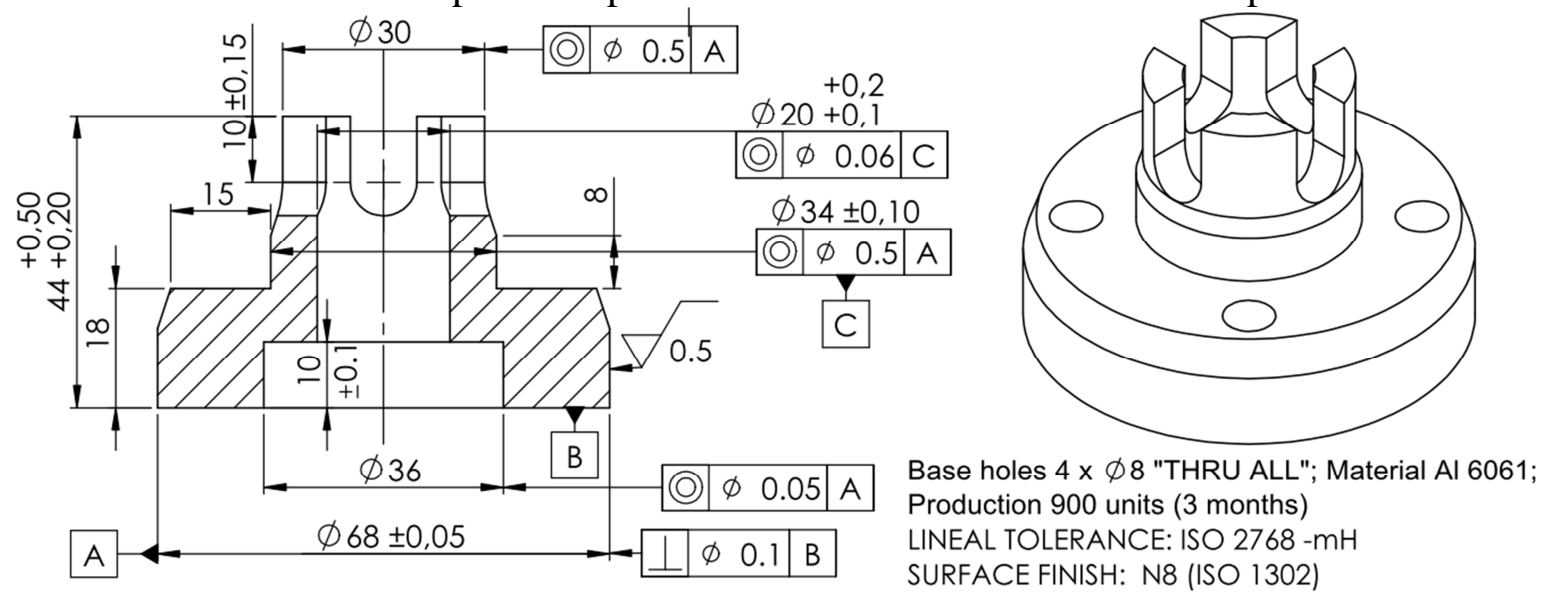

Figure 3. Example of technical drawings provided for the project.

Then, a computer session is used to learn how to design patterns with SolidWorks given the final parts. The concepts of machining allowance, drafts, shrinkage and runner, riser and sprue design are covered and the application of these concepts to the project is done and reviewed in seminar 2. After discussing the proposed pattern designs with the instructor, the validated patterns are then ready to be printed in our 3D printer machine using a Polylactic Acid (PLA) filament, a vegetable-based plastic material commonly used in $3 \mathrm{D}$ printing. The patterns printed are used to create the plates that will be mounted in the sand boxes to create the cavities for casting in shopfloor 2 (Figure 4). The most significant difficulties at this stage experienced by the students were the creation of the sand moulds due to the collapse of the cavity when releasing the pattern. One group had to redo the mould up to fourteen times to correctly obtain the mould. This group did not design properly the pattern and the drafts designed were too low for releasing the pattern without problems. Here, the instructor remarked the importance of a good pattern design to avoid this kind 
of problems, which was quite evident for the students after the repetition of the mould fourteen times.
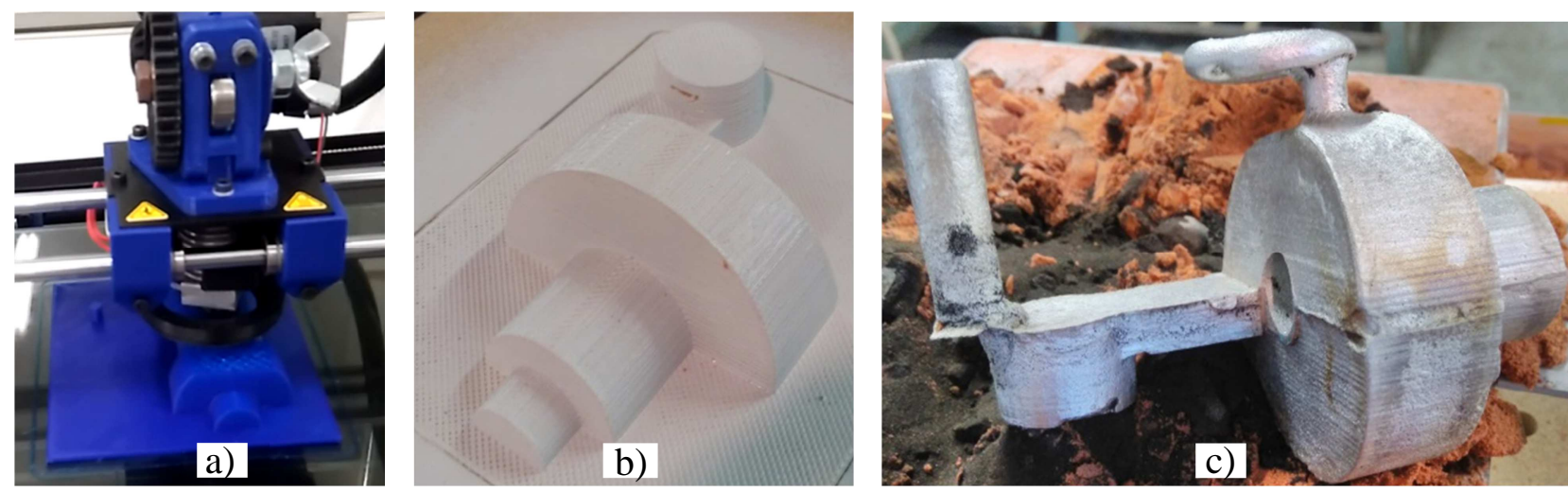

Figure 4. Real manufacturing results from students' activities. a) 3D printed patterns for the cope and drag to be used during sand casting; b) Pattern plate to be used for creating the drag (lower part of the sand mould); c) part obtained after casting.

At this stage, the casted parts are obtained and the students have to plan the machining process to manufacture the final part. Machine-tool, fixturing and cutting-tool selection is conducted together with the machining sequence and the geometric validation of the part through tolerance charting activities. The results of these activities are reported in the deliverable number 3 , and it is reviewed and discussed between the instructor and students. After all corrections are made, the students are ready to program the CNC code that is needed for machining the parts. To learn about the simulation of CNC code, two computer sessions are used to practice CNC programming. Then, the students elaborate the CNC programs to machine the parts in the project. A shop-floor session is used to simulate the programs in the machine-tools, check fixtures, check where the workpiece references are, how to clamp the parts, and other details. Then, in shop-floor 4 and 5 the programs elaborated by the students are launched in the CNC lathe and the CNC machining centre. After machining, the inspection of the part is conducted with a caliper, and it is checked if the part is within specifications according to the technical drawing. Figures 5 and 6 show some of the results at these stages of the project.

In the last week, each group presents their project results to the class and the final report is delivered before the last day of the semester.
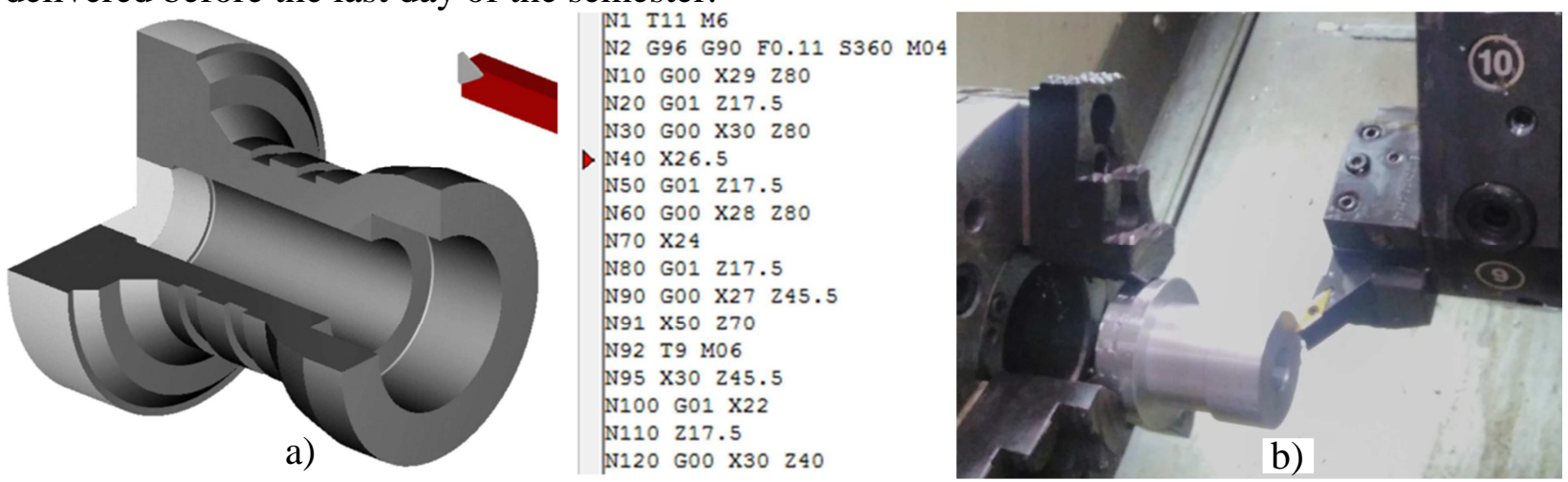

Figure 5. Real manufacturing results from students' activities: a) CNC simulation using WinUnisoft software; b) launch of the CNC program in the CNC lathe at the shop-floor. 

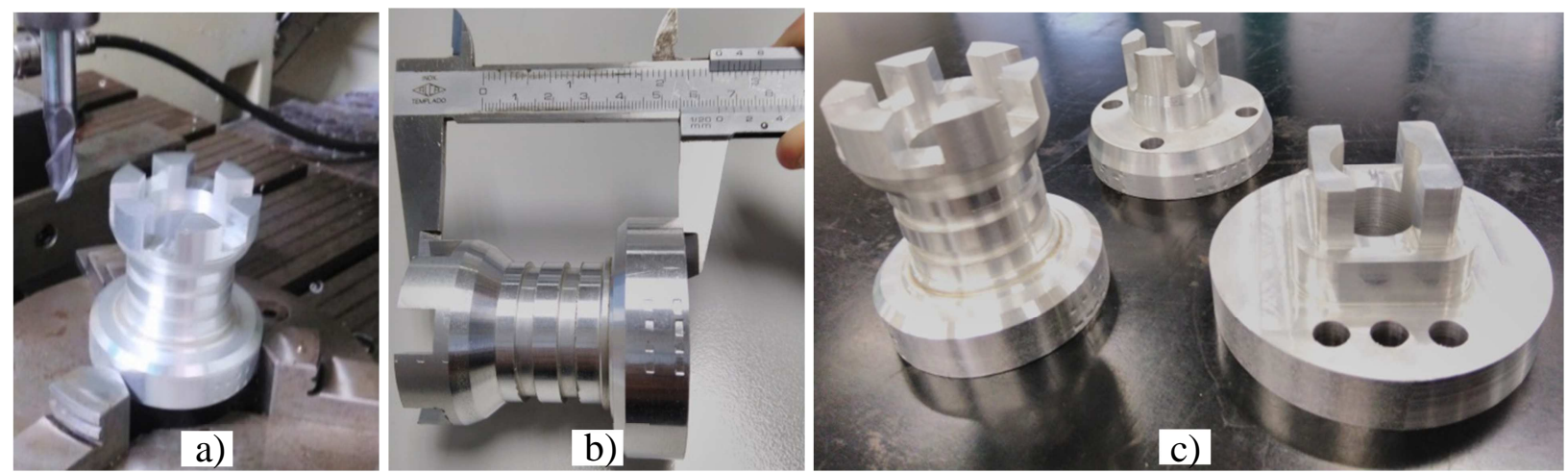

Figure 6. Real manufacturing results from students' activities: a) launch of the CNC program in the

$\mathrm{CNC}$ machining centre at the shop-floor; b) inspection activities to measure part quality and validate the manufacturing process; c) final parts obtained from different groups.

During the shop-floors many important problems related to real manufacturing arose which could not be observed and learnt without a real experiential approach. First, the part obtained after casting in one group was clamped in the 3-jaw chuck of the CNC lathe and the part crushed due to clamping forces (Figure 7-a). Due to this problem, the instructor asked the students to think about the possibility of reducing the clamping forces of the 3-jaw chuck to avoid the crush while ensuring enough fastening forces during machining. Some students proposed and justified the modification, but when machining the part the cutting force exceeded the 3-jaw forces and the part was released breaking the protection window of the lathe (Figure 7.b). The problem here was that the irregularities of the part from casting made that, in some point of the machining, the depth of cut was higher than the expected, exceeding the admissible clamping force and releasing the part. When trying to machine other parts, we saw that the crushed issue did not show up using the same clamping forces that the initial one. At this moment, we realize that the problem with the first part was not an excessive clamping force but a casting defect. Probably a cold shut occurred and the internal quality of the part was deficient producing the crush when clamping.

Other problems were related to mistakes made by the students in the CNC code. For instance, one part was not machined correctly because the coordinates programmed did not consider the machining allowance. Thus, part of the workpiece material was not removed and the final part had an additional cylindrical feature (Figure 7-c). Another interesting error is shown in Figure 7-d and refers to the deficient surface roughness of the internal surface of the part. This surface is machined by a boring cutting-tool with an important overhang. It was observed that the cutting conditions in this operation were too aggressive and the tool overhang produced steady vibrations that generate a deficient surface roughness.

It should be noted that all these errors cannot be detected if the parts are not manufactured and the students' challenge to understand and propose solutions to real errors is a key aspect that engineering curricula should face. Besides, the students understanding of manufacturing problems is greatly increased since the problems come from their manufacturing proposals and they see in situ the problems interacting with the instructor to find the possible solution. 

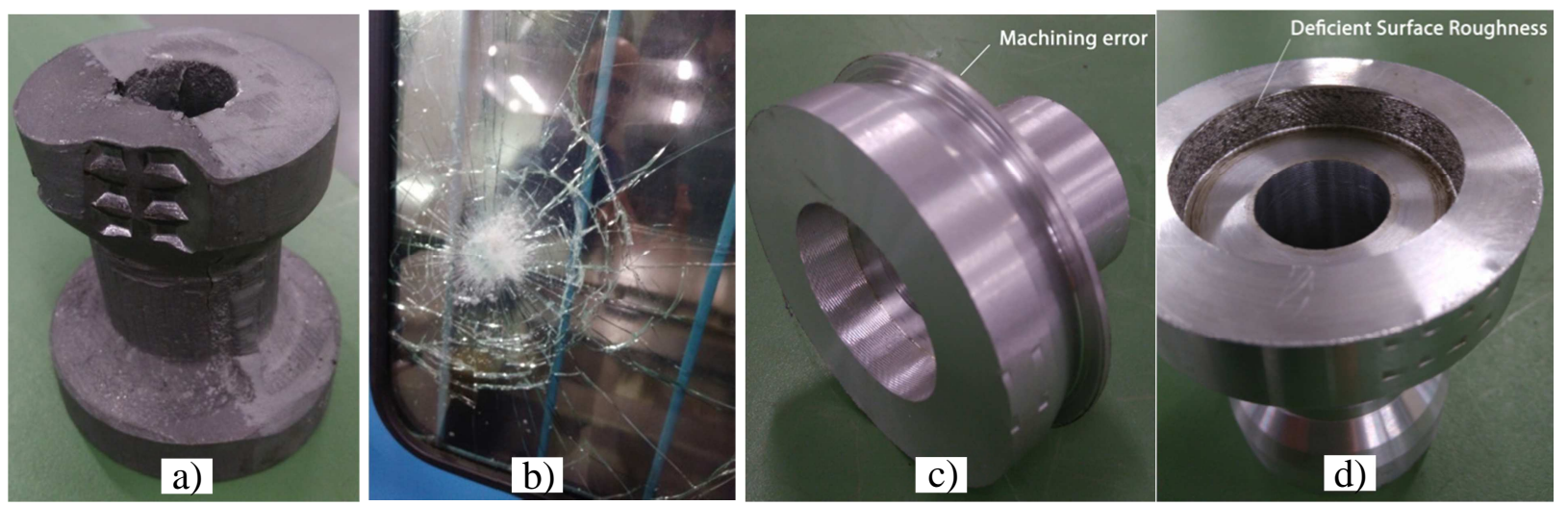

Figure 7. Problems during the 2-year experience. a) crush of the workpiece after clamping due to casting defects (probably a cold shut problem which arises when two streams of molten metal do not join properly when the piece is being cast); b) Breakage of the protection window of the lathe due to low clamping force during machining; c) machining error due to a student's mistake about $\mathrm{X}-\mathrm{Z}$ coordinates in the $\mathrm{CNC}$ code; $\mathrm{d}$ ) deficient surface roughness of the internal surface due to an excessive overhang of the boring cutting-tool and incorrect cutting conditions.

\section{Results and discussion}

In general terms, the educational experience was positive and the students' engagement and satisfaction reported from the students during the project development was quite high. However, in order to evaluate the effectiveness of this educational approach, a more quantitative and objective assessment is required. For this purpose, three different analyses are conducted. First, the students' performance is compared between the last 4 years. The student's performance comparison considers three aspects: i) class attendance; ii) exam and project grades; and iii) number of students that enrol into a manufacturing master degree the following year. Please, remind that during the first 2 years (courses 2014/15 and 2015/16) the teaching methodology was based on traditional lectures, short problems and shop-floor and computer sessions. All the activities were not connected to each other and without the goal of manufacturing a real part. Therefore, many of the activities conducted were paper-based such as homeworks related to manufacturing process planning in casting and machining, although some shop-floor demonstrations were also conducted in casting and machining. During the last 2 years (course 2016/17 and 2017/18), the course follows the methodology explained in this paper and thus, the course contents were centred on developing a project for planning the manufacturing activities of a given technical drawing that ends with the real manufacturing of the part. For the sake of clarity, the educational experience at the first two years is named the traditional approach and the one at the last two years is named proposed approach, where the proposed $\mathrm{PjBL}$ approach with experiential learning is applied.

Second, it is analysed the students' perception by studying a questionnaire that they have to complete at the end of each course. The students are asked to complete a questionnaire to answer questions related to their perception on: i) student's workload; ii) learning process; iii) student's motivation; iv) general satisfaction about the project. Furthermore, the questionnaire also included open-ended items for students to express their opinions about the project, and they are asked to write at least one positive and one negative aspect and one aspect that they would change for future years.

Third, the instructor's perception is also studied by another questionnaire. As instructors, we give our point of view in aspects related to: i) instructor's workload; ii) student's motivation; iii) engagement of students at theoretical classes; iv) perception of the learning process. 


\subsection{Students' performance comparison}

The results of students' performance for both traditional and proposed approaches are shown in Figure 8. The class attendance was expected to be higher in the proposed learning approach since all lectures are closely related to all project activities. One may think that the interest of learning the techniques to be applied in the project during the lectures should increase class attendance. However, the class attendance seems to be similar except for the last year, where it is clearly lower (see Figure 8-a). The missing point here is that in the last year, classes started at 8:00 a.m., unlike other years where classes started at 5:00 p.m. Furthermore, the last year, several students dropped out the course due to their jobs. Under these considerations, we may say that the attendance is similar in both methodologies as indicate the results from the third year (course 2016/17).

The results about the enrolment of students in a manufacturing master degree shown in Figure 8-b are clearly conclusive. Unlike the previous 2 years where only 2 from 27 students continued their studies in our manufacturing master degree, it seems that the proposed methodology increases the students' interest in manufacturing since 5 from 18 students finally enrolled in our manufacturing master degree. These results agree with the research in (42) where it is reported that project-based experiences can serve as a powerful tool for retaining students in engineering programs. However, a medium/long term evaluation should be necessary to confirm the trend.
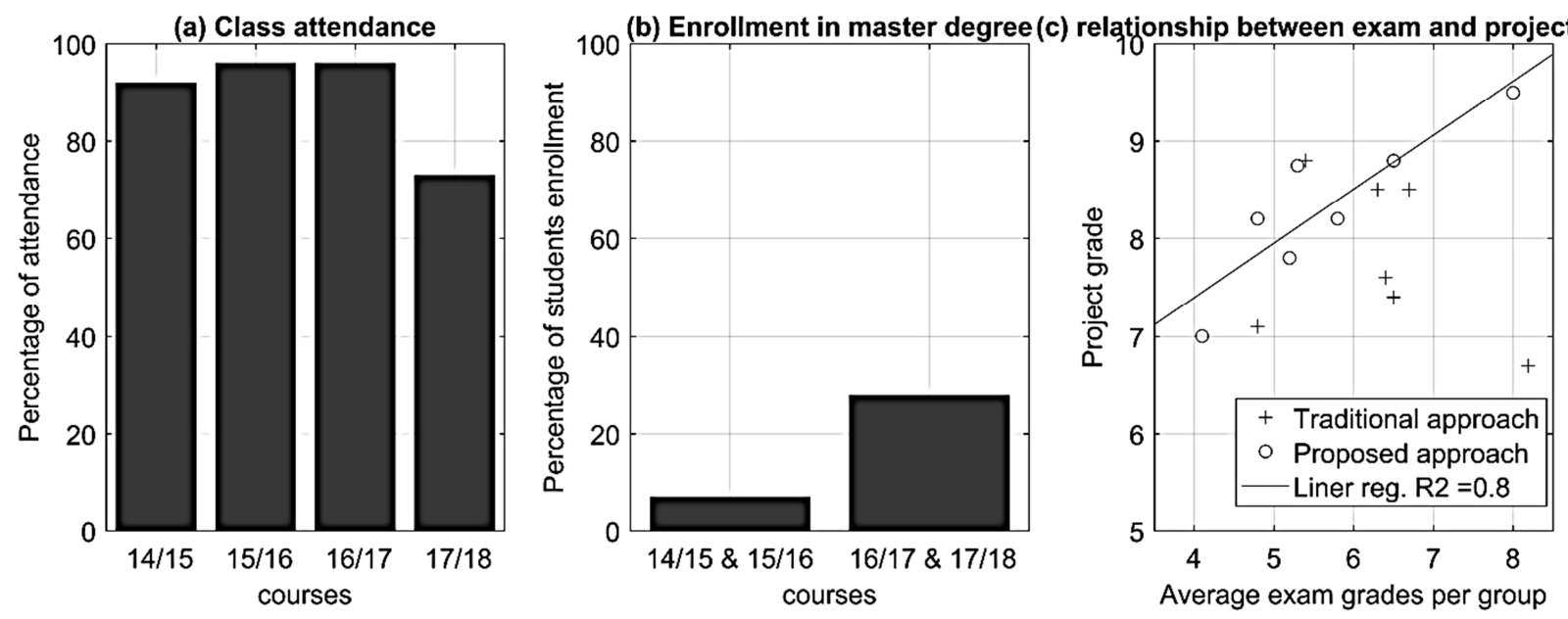

Figure 8. Students' performance: a) class attendance; b) Students that enrol the following year in a manufacturing master degree; c) correlation of exam and project grades.

Another interesting aspect about the comparison of students' performance between both learning approaches is shown in Figure 8-c. This graph shows the relationship between the average exam grade of the members of each group and the project grade. One may think that a good projectbased experience should boost the learning process and thus, the solution provided in the projects should serve the students to improve their knowledge and have a better performance during the exam. On the other hand, if the students do not work well during the project, it would be harder for the students to master the contents of the course. Under this hypothesis, a good project experience should show a high correlation between project grades and exam grades. If the average grade of the exams of all members of one group is low but the performance at the project was high, it seems that the lessons learnt during the project do not help the students in the learning process. In Figure 8-c, it is shown the relationship between exam and project grades for both traditional and proposed approaches. It can be noticed that the proposed learning approach helps the student to improve their performance at the exam (linear regression with coefficient of determination around $80 \%$ ), while in previous years the project grades were not correlated with the exam grades (no linear regression is available), meaning that the activities in the traditional approach were not well-designed. At this point it should be noted that these results could be influenced by different aspects such as the students' grades from previous courses (overall entry grade), students' skills in English (the course is taught in English), students' availability for working in groups, etc. In this 4-year experience, the 
characteristics of the students enrolled in the course have been rather homogeneous: overall entry grade of $6.3 \pm 0.6$ on a scale of 0-10, English level B1-B2 and availability for working in groups since they were not yet employed.

\subsection{Students' perception}

In order to analyse the students' perception on the educational experience, we study the results of two questionnaires. The first questionnaire is the official questionnaire that the university asks the students to complete at the end of each semester in all courses. Although there are many questions about the student's satisfaction in this questionnaire, for comparison purposes we only consider the average satisfaction of the students at each academic year. The second questionnaire is prepared to ask the students about their opinion of the proposed approach, and it was provided at the end of the course in the last two academic courses. All questionnaires were anonymous and individual.

The results from the first questionnaire reported an average student's satisfaction of 4.04 points over 5 for courses 14/15 and 15/16 with a standard deviation of 0.49 . These values come from the answers of 23 students. For the courses $16 / 17$ and $17 / 18$, the average student's satisfaction is 4.42 over 5 from 17 answers. In order to analyse if the proposed methodology increases the student's satisfaction reported in the official questionnaire, the following statistical hypothesis testing is conducted:

$$
\begin{aligned}
& H_{0}: \mu=4.04 \\
& H_{1}: \mu>4.04
\end{aligned}
$$

where $\mu$ is the average student's satisfaction of the students population when the proposed approach is applied. The questionnaire gives a 4.42 points of average satisfaction from 17 samples and the ttest statistic with and $\alpha$ level of 0.05 is 3.2 which mean a maximum value of 4.21 to reject the null hypothesis. Since the average satisfaction is 4.42 , we can reject the null hypothesis and confirm that the proposed approach significantly improves the student's satisfaction about the course around $10 \%$.

The second questionnaire asks the students about: i) hours dedicated to the project; ii) perception of the learning process; iii) project influence on student's motivation; iv) student's satisfaction on project activities. The results are shown in Figure 9. According to the answers, the degree of students satisfaction about the proposed approach is really high: all students believe that this project improved their learning process (83\% of students agreed that the learning process was much more better); all the students considered that this approach was motivating (58\% answered that was very motivating and $42 \%$ motivating); and the students' satisfaction on project activities was high. However, more than half of the students $(58 \%)$ considered that the workload of the project was higher than the 60 hours that were expected to be needed according to the characteristics of the course (6 ECTS and $40 \%$ of the grade is based on the project).

Additionally, the questionnaire presents some open-ended questions about: i) positive aspects of the project; ii) negative aspects of the project; and iii) modifications suggested for next years. As positive aspects, almost the $70 \%$ of the students answered about the real contact to shopfloor activities and $30 \%$ about the better understanding of the theoretical concepts thank to the real experimentation. As negative aspects, $42 \%$ of the students considered too much workload for the project, $20 \%$ complained about the low weight of the project to the final grade of the course, $20 \%$ reported the difficulty of following the theoretical classes due to the language (the course was taught in English according to the course specifications while all the students are Spanish), and other issues were reported in the remaining $18 \%$. It can be seen that the main problem of this approach, according to the students, is the workload which has been also reported by other researchers when project-based experiences are conducted $(3,29,34)$. It is reasonable that the main 
suggestions reported by the students for next years are related to the increase of the weight of the project grade over the course grade in order to compensate for the workload dedicated in comparison with the exam. This demand was written in the $35 \%$ of the questionnaires.

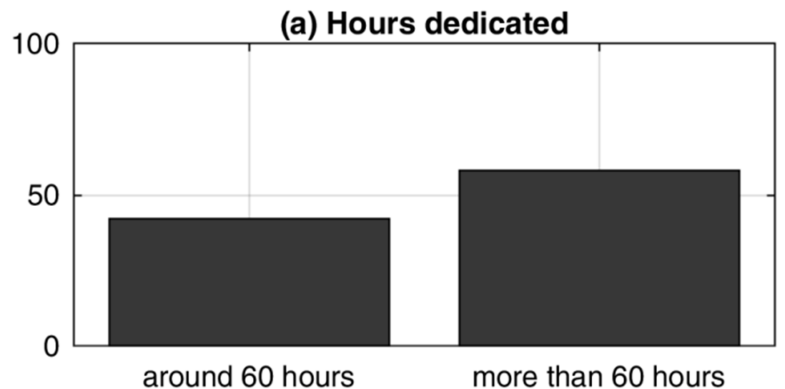

(c) Students motivation

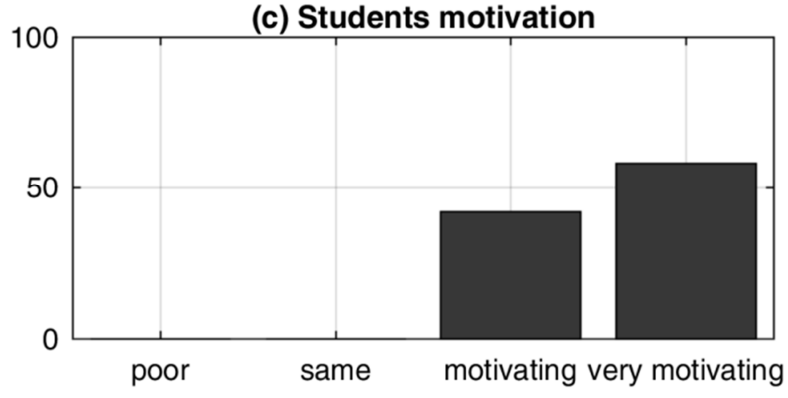

(b) Perception of learning process

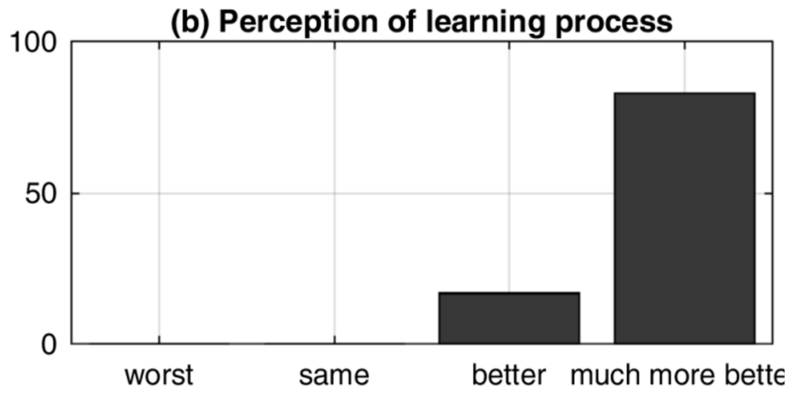

(d) Overall students satisfaction

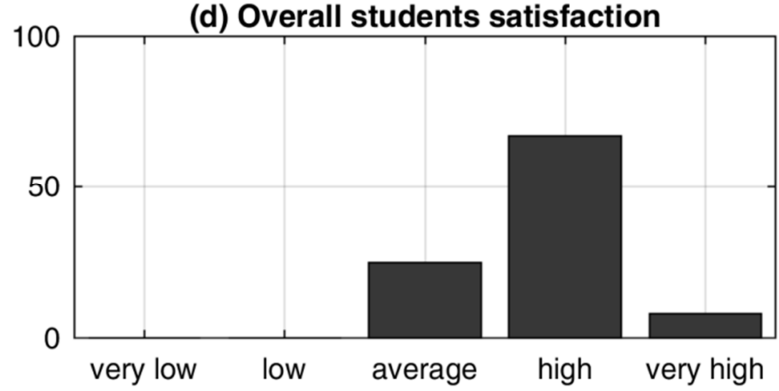

Figure 9. Student's answers to the questionnaire.

\subsection{Instructor's perception}

From the instructor's point of view, the main issue in this educational experience is the excessive workload that the instructor should bear in order to successfully manufacture the parts. For instance, all pattern designs should be checked to validate if the creation of the mould is feasible (e.g., correct core dimensions, correct drafts, etc.) and the CNC code should be carefully reviewed in order to detect potential problems before launching the program in the machine-tools. Note that in this course there is no teaching assistants or technicians that directly work with the students. Therefore, the proposed project-based approach could be manageable only if the size of the class is around 15 students or less, which means 4-5 groups of 3-4 students and 4-5 parts to be manufactured. In a course with a larger number of students we do not recommend this experience and an alternative in these cases could be the simulation of casting and machining processes through software. However, we believe that the real contact with the manufacturing process and the execution of the student activities at the shop-floor makes the student have a realistic view of the difficulties and problems of their designs.

Due to the nature of PjBL activities, the collaboration among the students of each team is a critical issue. In this experience we observed problems of collaboration in one group where tasks were completely divided in order to finish the project with minimum interaction. After warning the students we found out that one student worked outside the university and had low availability to work in group. Other expected problems in $\mathrm{PjBL}$ could be poor group participants or conflicts between them. In order to rapidly identify these issues, we highly recommend the use of seminars to evaluate the progress of the project and interact with all members of the group. Note that if proper actions are not taken at the early stages of the project some of the curriculum topics could not be covered as expected due to task division practices and some students may fail to engage the course. Helle et al. (29) also reported this issue in their work and remarked the challenge for promoting the student responsibilities to learn about all aspects of the subject instead of specializing in some specific aspects. To avoid this instructor's concern, we believe in the importance of co-assessment 
and the use of the project presentation as a tool to inquire through questions and answers if all students in the group have cooperated throughout the project.

Unlike student's perception, we do not agree with the main student's criticism about the project which relies on the excessive time dedicated to the project. In our opinion, the problem when working in groups is the inefficient use of time among students. Students are not used to work in groups and collaboration and coordination are important drawbacks. Some basics of how to work in groups efficiently should be incorporated at the beginning of the project in order to overcome this issue. However, previous $\mathrm{PjBL}$ experiences in the literature also reported that the time-consuming nature of this approach is a negative aspect that should be considered in advance by the instructors $(3,29,34)$.

In relation to students' motivation, we have a bittersweet feeling. During shop-floor and computer room activities, the students had a very active interaction with the instructor and we can notice a high engagement and excitement in students' activities. However, according to the instructor's opinion, the students did not show interest during lecturing sessions even though they were closely related to the project activities. Here, we should take into account that the lectures were given in English while the students are Spanish, so the language is probably the main reason of this lack of motivation and interaction since the average English level of the course, after a test at the beginning of the semester, is B1, not enough to follow an English lecture properly. Therefore, we are considering the application of the active learning strategy flipped classroom in some lectures in order to increase the interaction with the students and increase the engagement during the theoretical activities of the course. Interesting education experiences about flipped classroom can be found in (43).

\section{Conclusions}

In this paper we have shown how to apply an active learning approach in a 4-year mechanical engineering course named Manufacturing Process Planning. Unlike previous project based learning methodologies, we have proposed a project based learning methodology supported by experiential learning activities, mainly shop-floor activities with the purpose of manufacturing a real part. Under this approach, the students have to plan and conduct all manufacturing activities to manufacture the part assigned by the instructor. These activities are: manufacturing process selection; pattern design for casting; mould construction and casting; machining process planning (cutting-tool selection, fixture selection, cutting parameters selection), geometric validation using chart tolerances, and inspection.

The paper has shown that working at shop-floor level with the students is highly positive for the students' performance, motivation and engagement. For instance, the student's satisfaction about the course from other years was increased $10 \%$, all the students from the 2 year experience agreed that the learning process was better or much more better through this methodology, and all of them defined the project as motivating or very motivating. The project clearly increased the student's performance in the exam and the number of students that enrol in a manufacturing master degree increase from $7 \%$ to $28 \%$ showing that student's perception on manufacturing processes has improved even to consider manufacturing a field of interest for their professional career. However, the negative aspect of this approach is mainly the high workload that both students and instructors have to deal with. If the size of the class is appropriate, the authors encourage the application of project-based learning methodologies with real manufacturing activities when teaching manufacturing courses. In this kind of courses, classes are usually too conceptual or descriptive, and the rate of students' disengagement tends to be high. The adoption of adequate active learning methodologies as the one presented in this paper can be a good strategy to overcome these drawbacks. 


\section{References}

1. Spinks N, Silburn N, Birchall D. Educating engineers for the 21st century: The industry view. London R Acad Eng. 2006;

2. Edgerton R. Education white paper. 2001.

3. Mills JE, Treagust DF. Engineering education-Is problem-based or project-based learning the answer. Australas J Eng Educ. 2003;3(2):2-16.

4. ENAEE. Standards and Guidelines for Accrediation of Engineering Programs. European Network for Accreditation of Engineering Education. 2017.

5. Felder RM, Silverman LK. Learning and teaching styles in engineering education. Eng Educ. 1988;78(7):674-81.

6. George MD, Bragg S. Shaping the future: New expectations for undergraduate education in science, mathematics, engineering and technology. Washington, DC; 1996.

7. Vygotsky L. Interaction between learning and development. Readings Dev Child. 1978;23(3):34-41.

8. de Vere I. Developing creative engineers: a design approach to engineering education. Glob Eng Alliance Res Educ (GEARE)-A Compr Study Intern Abroad Progr Eng Students. 2009;

9. Bonwell CC, Eison JA. Active Learning: Creating Excitement in the Classroom. 1991 ASHE-ERIC Higher Education Reports. ERIC; 1991.

10. Freeman S, Eddy SL, McDonough M, Smith MK, Okoroafor N, Jordt H, et al. Active learning increases student performance in science, engineering, and mathematics. Proc Natl Acad Sci. 2014;111(23):8410-5.

11. Prince MJ, Felder RM. Inductive Teaching and Learning Methods: Definitions, Comparisons, and Research Bases. J Eng Educ. 2006;95(2):123-38.

12. Lima RM, Andersson PH, Saalman E. Active Learning in Engineering Education: a (re)introduction. Eur J Eng Educ. 2017;42(1):1-4.

13. Kollöffel B, Jong T. Conceptual understanding of electrical circuits in secondary vocational engineering education: Combining traditional instruction with inquiry learning in a virtual lab. J Eng Educ. 2013;102(3):375-93.

14. Douglas EP, Chiu C-C. Implementation of Process Oriented Guided Inquiry Learning (POGIL) in Engineering. Adv Eng Educ. 2013;3(3):n3.

15. Abdul-Kahar R, Esa F, Tay KG, Hashim R, Laham MN, Wong BYL. Finite Element Analysis (FEA) in Electronics Devices and Photonics through Process Oriented Guided Inquiry Learning (POGIL). J Telecommun Electron Comput Eng. 2016;8(6):93-7.

16. Prince M, Felder R. The many faces of inductive teaching and learning. J Coll Sci Teach. 2007;36(5):14.

17. Marrs KA, Novak G. Just-in-time teaching in biology: creating an active learner classroom using the internet. Cell Biol Educ. 2004;3(1):49-61.

18. Slunt KM, Giancarlo LC. Student-centered learning: A comparison of two different methods of instruction. J Chem Educ. 2004;81(7):985.

19. Perrenet JC, Bouhuijs PAJ, Smits JGMM. The Suitability of Problem-based Learning for Engineering Education: Theory and practice. Teach High Educ [Internet]. 2000;5(3):345-58. Available from: http://www.tandfonline.com/doi/abs/10.1080/713699144

20. Hmelo-Silver CE. Problem-based learning: What and how do students learn? Educ Psychol Rev. 2004;16(3):235-66. 
21. Yadav, A., Shaver, G. M., \& Meckl P. Lessons learned: Implementing the case teaching method in a mechanical engineering course. J Eng Educ. 2010;

22. Vivas JF, Allada V. Enhancing engineering education using thematic case-based learning. Int J Eng Educ. 2006;22(2):236.

23. Kolb DA. Experiential learning: Experience as the source of learning and development. FT press; 2014.

24. Abdulwahed M, Nagy ZK. Applying Kolb's experiential learning cycle for laboratory education. J Eng Educ. 2009;98(3):283-94.

25. Verner IM, Ahlgren DJ. Robot contest as a laboratory for experiential engineering education. J Educ Resour Comput. 2004;4(2):2.

26. Chandrasekaran S, Stojcevski A, Littlefair G, Joordens M. Learning through projects in engineering education. In: SEFI 2012: Engineering Education 2020: Meet The Future: Proceedings of the 40th SEFI Annual Conference 2012. 2012.

27. Puente SMG, van Eijck M, Jochems W. A sampled literature review of design-based learning approaches: a search for key characteristics. Int J Technol Des Educ. 2013;23(3):717-32.

28. Gómez Puente SM, van Eijck M, Jochems W. Towards characterising design-based learning in engineering education: a review of the literature. Eur J Eng Educ [Internet].

2011;36(2):137-49. Available from:

http://www.tandfonline.com/doi/abs/10.1080/03043797.2011.565116

29. Helle L, Tynjälä P, Olkinuora E. Project-based learning in post-secondary education--theory, practice and rubber sling shots. High Educ. 2006;51(2):287-314.

30. Lantada AD, Morgado PL, Munoz-Guijosa JM, Sanz JLM, Varri Otero JE, García JM, et al. Towards successful project-based teaching-learning experiences in engineering education. Int J Eng Educ [Internet]. 2013;29(2):476-90. Available from:

http://www.scopus.com/inward/record.url?eid=2-s2.0-

84875352674\&partnerID=40\&md5=b7530554f2c424f8ae64a35a07577b16

31. Blumenfeld PC, Soloway E, Marx RW, Krajcik JS, Guzdial M, Palincsar A. Motivating project-based learning: Sustaining the doing, supporting the learning. Educ Psychol. 1991;26(3-4):369-98.

32. Frank M, Lavy I, Elata D. Implementing the project-based learning approach in an academic engineering course. Int J Technol Des Educ. 2003;13(3):273-88.

33. Hadim HA, Esche SK. Enhancing the Engineering Curriculum Through Project-Based Learning. Front Educ. 2002;F3F-1-F3F-6.

34. Palmer S, Hall W. An evaluation of a project-based learning initiative in engineering education. Eur J Eng Educ. 2011;36(4):357-65.

35. Vila C, Abellán-Nebot JV, Estruch AM, Siller HR. Collaborative product development experience in a senior Integrated manufacturing course. Int J Eng Educ. 2009;25(5):886-99.

36. Vila C, Ugarte D, Ríos J, Abellán JV. Project-based collaborative engineering learning to develop Industry 4.0 skills within a PLM framework. Procedia Manuf [Internet]. 2017;13:1269-76. Available from: https://doi.org/10.1016/j.promfg.2017.09.050

37. Ríos IDL, Cazorla A, Díaz-Puente JM, Yagüe JL. Project-based learning in engineering higher education: Two decades of teaching competences in real environments. Procedia - Soc Behav Sci [Internet]. 2010;2(2):1368-78. Available from:

http://dx.doi.org/10.1016/j.sbspro.2010.03.202

38. Kirschner PA, Sweller J, Clark RE. Why minimal guidance during instruction does not work: 
An analysis of the failure of constructivist, discovery, problem-based, experiential, and inquiry-based teaching. Educ Psychol. 2006;41(2):75-86.

39. Holubova R. Effective teaching methods - Project-based learning in physics. US-China Educ Rev [Internet]. 2008;5(12):27-36. Available from:

http://files.eric.ed.gov/fulltext/ED504949.pdf

41. Jollands M, Jolly L, Molyneaux T. Project-based learning as a contributing factor to graduates' work readiness. Eur J Eng Educ. 2012;37(2):143-54.

42. Richardson J, Corleto C, Froyd J, Imbrie PK, Parker J, Roedel R. Freshman design projects in the Foundation Coalition. In: Frontiers in Education Conference, 1998 FIE'98 28th Annual. 1998. p. 50-9.

43. Bishop J, Verleger M. Testing the flipped classroom with model-eliciting activities and video lectures in a mid-level undergraduate engineering course. Proc - Front Educ Conf FIE. 2013;161-3.

44. Abele E, Metternich J, Tisch M, Chryssolouris G, Sihn W, ElMaraghy H, et al. Learning factories for research, education, and training. In: Procedia CIRP. 2015. p. 1-6.

45. Lamancusa JS, Jorgensen JE, Zayas-Castro JL, Ratner J. The Learning Factory - A new approach to integrating design and manufacturing into engineering curricula. ASEE Conf Proc. 1995;

46. Ssemakula, Mukasa E and Liao GY. Adaptation of the learning factory model for implementation in a manufacturing laboratory. In: Proceedings of the American Society for Engineering Education Annual Conference \& Exposition. 2003.

47. Malicky DM, Kohl JG, Huang MZ. Integrating a Machine Shop Class into the Mechanical Engineering Curriculum: Experiential and Inductive Learning. Int J Mech Eng Educ. 2010; 